\title{
The Relationship of Products, Brands, and Promotions to Purchase Decisions for Honda Beat Motorcycles in Bengkulu City (Case Study at Nusantara Sakti Company, Bengkulu City)
}

\section{Hubungan Produk, Merek, dan Promosi Terhadap Keputusan Pembelian Sepeda Motor Honda Beat di Kota Bengkulu (Studi kasus pada Perusahaan Nusantara Sakti Kota Bengkulu)}

\author{
By Kasdi 1); Rudi Hartono1); Edwarman 1) \\ 1,2,3)Sekolah Tinggi Ilmu Administrasi Bengkulu \\ Email: ${ }^{1)}$ buyungkasdi1@gmail.com
}

\begin{abstract}
How to Cite :
Kasdi, B., Hartono, R., Edwarwan. (2022). The Relationship of Products, Brands, and Promotions to Purchase Decisions for Honda Beat Motorcycles in Bengkulu City (Case Study at Nusantara Sakti Company, Bengkulu City). Jurnal Ekonomi Manajemen Akuntansi Dan Keuangan, 3(1). DOI: https://doi.org/10.53697/emak.v3i1
\end{abstract}

\section{ARTICLE HISTORY}

Received [30 Desember 2021]

Revised [07 Januari 2022]

Accepted [27 Januari 2022]

\section{KEYWORDS}

Relationship of Products, Brands, Promotions, Purchase Decisions

This is an open access article under the CC-BY-SA license

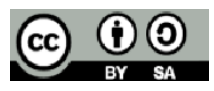

\section{ABSTRAK}

Penelitian ini bertujuan untuk menghubungkan produk, merek, dan promosi terhadap keputusan pembelian sepeda motor honda beat di Kota Bengkulu. Tujuan dari penelitian ini adalah mengungkap fakta, keadaan, fenomena, variabel dan keadaan yang terjadi saat penelitian berjalan dan menyuguhkan apa adanya. Penelitian deskriptif kualitatif menafsirkan dan menuturkan data yang bersangkutan dengan situasi yang sedang terjadi, sikap serta pandangan yang terjadi di dalam masyarakat, pertentangan 2 keadaan / lebih, hubungan antarvariabel, perbedaan antar fakta, pengaruh terhadap suatu kondisi, dan lain-lain. Jenis penilitian ini menggunakan penelitian deskriptif kualitatif. Penelitian deskriptif kualitatif merupakan penelitian yang termasuk dalam jenis penelitian kualitatif. Hasil pengujian rank spearman terdapat hubungan yang kuat antara produk dengan keputusan pembelian sepeda motor Honda Beat pada PT. Nusantara Surya Sakti Cabang Bengkulu dengan nilai korelasi sebesar 0,646. Untuk Nilai korelasi rank spearman hubungan Merk terhadap keputusan pembelian sepeda motor Honda Beat pada PT. Nusantara Surya Sakti Cabang Bengkulu dengan nilai korelasi sebesar 0,707 dengan kriteria penelitian kuat. Dan Nilai korelasi rank spearman untuk hubungan Promosi terhadap keputusan pembelian sepeda motor Honda Beat pada PT. Nusantara Surya Sakti Cabang Bengkulu dengan nilai korelasi sebesar 0,815 dengan kriteria penilaian sangat kuat

\section{ABSTRACT}

This study aims to link products, brands, and promotions to purchasing decisions for Honda Beat motorcycles in Bengkulu City. The purpose of this research is to reveal facts, circumstances, phenomena, variables and circumstances that occurred during the research and present what is. Qualitative descriptive research interprets and tells data related to the current situation, attitudes and views that occur in society, contradictions of 2 or more circumstances, relationships between variables, differences between facts, influence on a condition, and others. This type of research uses descriptive qualitative research. Qualitative descriptive research is research that is included in the type of qualitative research. The results of

306 | By Kasdi, Rudi Hartono, Edwarman; The Relationship of Products... 
the Spearman rank test have a strong relationship between the product and the decision to purchase a Honda Beat motorcycle at PT. Nusantara Surya Sakti Bengkulu Branch with a correlation value of 0.646. For the Spearman rank correlation value, the brand's relationship to the decision to purchase a Honda Beat motorcycle at PT. Nusantara Surya Sakti Bengkulu Branch with a correlation value of 0.707 with strong research criteria. And the Spearman rank correlation value for the relationship between promotions and purchasing decisions for Honda Beat motorcycles at PT. Nusantara Surya Sakti Bengkulu Branch with a correlation value of 0.815 with very strong assessment criteria.

\section{PENDAHULUAN}

Semakin banyaknya produk sepeda motor yang berdiri di kota besar yang salah satunya di kota Bengkulu, memacu para pengusaha sepeda motor untuk memaksimalkan dalam mempertahankan atau meningkatkan perusahaan agar dapat bersaing dengan perusahaan sejenis lainnya. Seiring dengan perkembangan jaman dan semakin meningkatnya kebutuhan alat transportasi membawa angin segar bagi perusahaan otomotif terutama di bidang sepeda motor, yang mana sangat dibutuhkan oleh banyak konsumen, selain harganya yang terjangkau dan mudah perawatannya.

Pertumbuhan konsumen sepeda motor meningkat luar biasa. Di tengah-tengah persaingan yang begitu tajam akibat banyaknya merek pendatang baru, sepeda motor Honda yang sudah lama berada di Indonesia dengan segala keunggulannya, tetap mendominasi pasar dan sekaligus memenuhi kebutuhan angkutan yang tangguh, irit dan ekonomis. Menjawab tantangan tersebut, organisasi yang berada di balik kesuksesan sepeda motor Honda di Indonesia terus memperkuat diri.

Keunggulan teknologi motor Honda diakui di seluruh dunia dan telah dibuktikan dalam berbagai kesempatan, baik dijalan raya maupun di lintasan balap. Honda pun mengembangkan teknologi yang mampu menjawab kebutuhan pelanggan yaitu mesin "bandel" dan irit bahan bakar, sehingga menjadikannya sebagai pelapor kendaraan roda dua yang ekonomis.

Berdasarkan hal tersebut, maka analisis mengenai keputusan pembelian sangat penting dilakukan oleh perusahaan-perusahaan yang memasarkan produk Sepeda motor. Hal tersebut perlu dilakukan agar perusahaan dapat selalu meningkatkan volume penjualan yaitu melalui analisa faktor atau atribut apa saja yang menjadi pertimbangan konsumen dalam membeli sepeda motor. Karena sesungguhnya masing-masing konsumen tentu memiliki motif yang berbeda dalam melakukan pembelian sepeda motor.

Mengawali tahun 2016, PT Astra Honda Motor (AHM) meluncurkan sepeda motor skutik New Honda BeAT POP eSP dengan desain stripe terbaru yang atraktif sesuai trend remaja terkini. Tampilan terbaru skutik Honda ini dipersembahkan untuk para remaja yang menginginkan sepeda motor berdesain fun dan atraktif, irit BBM, serta lincah dengan bodinya yang ramping.

New Honda BeAT POP eSP kini hadir melalui dua desain stripe yakni Cool Pixel dan Comic Hits. Stripe Cool Pixel mengusung tema pixelate image dengan 5 pilihan, yakni warna Harmony Black White untuk tipe CW, CBS, CBS-ISS dan warna Groovy Red White untuk tipe CBS, CBS-ISS. Sementara itu Stripe Comic Hits mengusung tema pop-art comic image dengan 4 pilihan, yaitu warna Tone Black untuk tipe CW, warna Melody Blue White untuk Tipe CBS, CBS-ISS dan warna Voice Magenta White untuk tipe CBS-ISS. Keseluruhan stripe ini semakin memberikan pilihan sesuai dengan karakter grafis yang dihadirkan.

Dengan mengandalkan slogannya "Motor Matic Gaul dan Irit" Honda Beat diharapkan mampu memenuhi kebutuhan seluruh anggota keluarga tanpa melupakan unsur ekonomis (hemat bbm dan perawatan) yang sudah menjadi positioning sepeda motor Honda. Walaupun 
bukan motor khusus wanita pertama di Indonesia dan juga bukan cuma mencoba membidik motor khusus untuk gender cewek tetapi, juga dapat membuat banyak lelaki jatuh cinta pada motor ini.

Honda Beat mampu menyaingi produk sepeda motor saingannya, Honda Beat mempunyai desain dan body yang lebih ramping serta disertai sistem brake lockberfungsi sebagai rem tangan, side stand switch yang fungsinya agar mesin tidak dapat dinyalakan saat standar samping dalam posisi turun, dan kapasitas mesin lebih ringan membuat sepeda motor ini lebih irit bahan bakar dibanding sepeda motor matic lainnya yang sudah dikenal sangat boros.

Perilaku konsumen menjadi salah satu faktor yang perlu dipertimbangkan dalam usaha pemasaran produk. Strategi pemasaran yang tepat merupakan salah satu cara ntuk mencapai tujuan perusahaan yaitu dengan mengetahui kebutuhan dan keinginan konsumen sehingga tercipta produk yang tepat. Dengan demikian peningkatan volume penjualan dan memenangkan persaingan dapat tercapai. Begitu juga dilakukan para produsen sepeda motor matic seiring dengan permintaan yang semakin meningkat. Dengan penggunaan perilaku konsumen tersebut tampaknya memberikan dampak positif bagi Honda Beat. Hal ini dapat dilihat tercatat volume penjualan Honda Beat pada tahun 2015 sebagai berikut :

jika dilihat dari data dala tabel 1 di atas, volume penjualan Honda Beat meningkat dari bulan Oktober penjualan sebesar 33 unit sampai bulan November dan Desember penjualan sebesar 35 dan 37 unit. Hal ini menunjukkan bahwa kualitas Honda Beat yang dapat dipercaya. Tetapi dapat dilihat juga pada bulan Februari Maret, April, mengalami penurunan dari 30 unit turun menjadi 26 unit, bulan Maret dari 26 unit turun menjadi 24 unit.

Selain peningkatan penjualan pada PT. Nusantara Surya Sakti Bengkulu, Berdasarkan data Asosiasi Industri Sepeda motor Indonesia (AISI) sepanjang Januari - November 2015, Honda BeAT series tercatat sebagai sepeda motor skutik terlaris di Indonesia dengan total penjualan mencapai 1.848.439 unit atau $41 \%$ dari total penjualan skutik nasional. Kontribusi model ini menjadi semakin memperkuat posisi Honda sebagai raja skutik nasional dengan angka penjualan 3.487.143 unit atau memimpin 77,5\% pangsa pasar skutik nasional pada periode yang sama. Hingga November 2015, Honda BeAT series telah menjadi pilihan lebih dari 9,7 juta konsumen tanah air sejak pertama kali diluncurkan pada Juni 2008.

Terdapat banyak faktor yang menyebabkan pelanggan sepeda motor memilih Honda Beat sebagai pilihannya. Mulai dari konsumsi bahan bakar yang irit, merek terkenal, kualitas dan kuantitas, sampai dengan beberapa faktor lainnya. Namun, yang paling menarik adalah faktor produk. Hal ini dikarenakan bahwa pada faktor inilah tingkat persaingan yang terjadi antar sepeda motor cukup tinggi. Ketika merek, harga, dan promosi sudah memuaskan pelanggan, maka yang dicari oleh para pelanggan adalah seberapa canggih dan banyak keunggulan yang dapat diperoleh oleh pelanggan.

Dengan melihat dari kondisi sepeda motor Honda Beat tersebut di atas, maka dapat disimpulkan bahwa meskipun terjadi kenaikan pada tahun 2015 namun target yang telah ditetapkan oleh Dealer Honda sendiri belum dapat terpenuhi. Sehubungan dengan hal tersebut, pemahaman terhadap faktor-faktor yang berpengaruh terhadap keputusan pembelian konsumen kiranya dapat menjadi acuan dalam merumuskan strategi untuk menghindari penurunan penjualan yang berkepanjangan. Stanton (1996) mengemukakan bahwa faktor yang berpotensi meningkatkan kemungkinan seorang konsumen untuk membeli suatu produk, yakni terkait dengan evaluasi terhadap kualitas produk, merek, keunikan produk dari segi desain, dan warna serta layanan yang diberikan.

Produk, merek, dan promosi menjadi salah satu tolak ukur bagi keberhasilan perusahaan untuk menarik minat konsumen. Hal ini karena konsumen akan berminat membeli terhadap suatu produk merek sepeda motor. Strategi pemasaran yang tepat merupsksn salah satu cara ntuk mencapai tujuan perusahaan yaitu dengan mengetahui kebutuhan dan keinginan konsumen sehingga tercipta produk yang tepat. Dengan demikian peningkatan volume penjualan dan memenangkan persaingan dapat tercapai. 
Begitu juga dilakukan para produsen sepeda motor matic seiring dengan permintaan yang semakin meningkat. Merek merupakan hal yang penting dalam menentukan suatu keputusan pembelian. Merek yang berhasil memiliki potensi yag besar untuk menghasilkan keuntungan lebih banyak lagi bila perusahaan mampu memnafaatkan merek tersebut secara agresif dan terus menerus melalui berbagai cara seperti perluasan merek atu perluasan lini. Bagi banyak bisnis, nama merek (brand name) dan apa yang dikandungnya merupakan hal terpenting sebagai basis strategi berssaing, dan sumber, pendapatan masa datang. Bagi perusahaan, merek bisa menjadi semakin bernilai karena dapat memanfaatkannya untuk membangun basis kepercayaan

konsumen dalam menentukan pilihan suatu produk. Betapapun berkualitasnya suatu produk, bila konsumen belum pernah mendengarnya dan tidak yakin bahwa produk itu akan berguna bagi mereka, maka mereka tidak akan pernah membelinya. Supaya merek suatu produk dikenal secara luas oleh konsumen maka perlu sekiranya penjual melakukan kegiatan pemasaran yang lain yaitu promosi. promosi adalah arus informasi atau persuasi satu arah yang dibuat untuk mengarahkan seseorang atau organisasi kepada tindakan yang menciptakan pertukaran dalam pemasaran.

\section{LANDASAN TEORI}

\section{Pengertian Pemasaran}

Pemasaran merupakan faktor penting dalam siklus yang berhubungan dengan pemenuhan kebutuhan konsumen. Dalam salah satu perusahaan, pemasaran merupakan salah satu dari kegiatan pokok yang dilakukan perusahaan untuk mempertahankan kelangsungan hidupnya,berkembang dan mendapatkan laba, kegiatan pemasaran perusahaan juga harus dapat memberikan kepuasan pada konsumen jika menginginkan usahanya tetap berjalan.

Sejak orang mengenal kegiatan pemasaran, telah banyak ahli mengemukakan definisi tentang pemasaran yang kelihatannya sedikit berbeda tetapi memiliki arti yang sama. Perbedaan ini disebabkan karena mereka meninjau pemasaran dari segi-segi yang berbeda, ada yang menitik beratkan pada segi fungsi, segi barang dan segi kelembagaan.

\section{Keputusan Pembelian}

Menurut Kotler dan Armstrong (2001:226) keputusan pembelian adalah tahap dalam proses pengambilan keputusan pembeli dimana konsumen benar benar akan membeli. Berdasarkan tujuan pembelian, konsumen dapat diklasifikasikan menjadi dua kelompok, yaitu konsumen akhir (individual) dan konsumen organisasional (konsumen industrial, konsumen antara, konsumen bisnis). Konsumen akhir terdiri atas individu atau rumah tangga yang tujuan akhirnya adalah untuk memenuhi kebutuhan sendiri atau untuk konsumsi. Sedangkan konsumen organisasional terdiri atas organisasi, pemakai industri, pedagang, dan lembaga non profit yang tujuan pembeliannya adalah untuk keperluan bisnis (memperoleh laba) atau meningkatkan kesejahteraan anggotanya.

Pada umumnya manusia bertindak rasional dan mempertimbangkan segala jenis informasi yang tersedia dan mempertimbangkan segala sesuatu yang mungkin bisa muncul dari tindakannya sebelum melakukan sebuah perilaku tertentu.

\section{Perilaku Konsumen}

Perilaku konsumen adalah tindakan yang langsung terlibat dalam menempatkan, mengkonsumsi dan menghabiskan produk jasa termasuk keputusanyang mendahului dan menyusun tindakan ini (Setiadi Nugroho, 2004:3). Maka dalam kehidupan sehari-hari, keputusan pembelian yang dilakukan oleh konsumen didasarkan pada pertimbangan yang berbeda-beda satu dengan yang lainnya.

Sementara itu perilaku konsumen dapat dipengaruhi melalui pemasaran yang terampil 
karena hal ini dapat membangkitkan motivasi maupun perilaku apabila hal tersebut didukung dengan produk ataupun jasa yang didesain semenarik mungkin dan sedemikian rupa guna memenuhi kebutuhan pelanggan (Engel dkk,1994). Kemudian Swastha dkk (1987) menambahkan adanya faktorfaktor yang mempengaruhi perilaku konsumen itu sendiri, disini disebutkan terdapat dua bagian besar yaitu faktor internal dan faktor eksternal.Untuk mempelajari lebih lanjut perilaku konsumen, Assael dalam Sutisna (2003:6) menggambarkan model perilaku konsumen yang membahas faktorfaktor yang mempengaruhi sebagai penyempurnaan lebih lanjut.

\section{METODE PENELITIAN}

\section{Metode Analisis Data}

Jenis penilitian ini menggunakan penelitian deskriptif kualitatif. Penelitian deskriptif kualitatif merupakan penelitian yang termasuk dalam jenis penelitian kualitatif. Tujuan dari penelitian ini adalah mengungkap fakta, keadaan, fenomena, variabel dan keadaan yang terjadi saat penelitian berjalan dan menyuguhkan apa adanya. Penelitian deskriptif kualitatif menafsirkan dan menuturkan data yang bersangkutan dengan situasi yang sedang terjadi, sikap serta pandangan yang terjadi di dalam masyarakat, pertentangan 2 keadaan / lebih, hubungan antarvariabel, perbedaan antar fakta, pengaruh terhadap suatu kondisi, dan lain-lain. masalah yang diteliti dan diselidiki oleh penelitian deskriptif kualitatif mengacu pada studi kuantitatif, studi komparatif, serta dapat juga menjadi sebuah studi korelasional 1 unsur bersama unsur lainnya. (singgih, 2004:14)

Metode analisis yang digunakan dalam penelitian ini adalah menggunakan Korelasi Rank Spearman dan uji hipotesis sebagai berikut :

\section{Korelasi Rank Spearman}

Menurut Sugiyono (2013 : 245), dalam Korelasi Rank Spearman data untuk kedua variabel yang akan dikonversikan dapat berasal dari sumber yang tudak sama, jenis data yang dikorelasikan adalah data ordinal, serta data dari kedua variabel tidak harus membentuk distribusi normal. Jadi Korelasi Rank Spearman adalah bekerja dengan data ordinal atau berjenjang atau rangking, dan bebas distribusi. Adapun rumus Korelasi Rank Spearman adalah:

$$
\begin{aligned}
& \rho=1-\frac{6 \sum b i^{2}}{n\left(n^{2}-1\right)} \\
& \text { (Sugiyono, 2013:245) } \\
& \text { Keterangan : } \\
& \rho=\text { Koefisien Korelasi Spearman Rank } \\
& \mathrm{n} \quad=\text { Jumlah sampel } \\
& \sum b i^{2}=\text { Jumlah kuadrat dari selisih rank variabel } \mathrm{X} \text { dan variabel } \mathrm{Y} \text {. }
\end{aligned}
$$

\section{HASIL DAN PEMBAHASAN}

\section{Hasil Uji Hipotesis}

Berdasarkan pengujian analisis korelasi rank spearman dan uji hipotesis uji t maka dapat dijelaskan hasil dari pengujian tersebut seperti pada tabel 2 di bawah ini :

Tabel 1. Hasil pengujian Korelasi Rank Spearman dengan Hipotesis

\begin{tabular}{|l|l|l|l|l|l|}
\hline NO & Variable & $\rho$ & Ket & thitung & ttable.(-2) \\
\hline 1 & Produk & 0,646 & Kuat & 5,483 & 1,681 \\
\hline 2 & Merk & 0,707 & Kuat & 6,480 & 1,681 \\
\hline 3 & Promosi & 0,815 & Sangat Kuat & 9,112 & 1,681 \\
\hline
\end{tabular}

Sumber : Data Diolah, 2016

310 | By Kasdi, Rudi Hartono, Edwarman; The Relationship of Products... 
Dari hasil pengujian rank spearman terdapat hubungan yang kuat antara produk dengan keputusan pembelian sepeda motor Honda Beat pada PT. Nusantara Surya Sakti Cabang Bengkulu dengan nilai korelasi sebesar 0,646 . Hal ini diperkuat dengan hasil pengujian hipotesis diketahui nilai thitung $=5,483$ lebih besar dari nilai ttable yaitu 1,681 atau $(5,483>1,681)$. Jadi nilai thitung lebih besar dari ttable. Berarti antara produk memiliki hubungan yang positif dan signifikan terhadap keputusan pembelian sepeda motor Honda Beat pada PT. Nusantara Surya Sakti Cabang Bengkulu. Hal ini memberikan makna bahwa produk, seperti mesin bandel, irit bahan bakar, performa mesin yang unggul telah mampu mendorong konsumen dalam melakukan keputusan pembelian sepeda motor Honda Beat.

Dengan demikian adanya produk dengan performa mesin yang unggul, keiritan bahan bakar, mesin yang bandel pada suatu produk sepeda motor dapat meningkatkan konsumen dalam melakukan keputusan pembelian. begitu pula

Sebaliknya apabila suatu produk tidak memiliki keunggulan maka bisa menurunkan konsumen dalam memutuskan pembelian produk sepeda motor, maka dari itu sebuah produk haruslah sesuai dengan standar keamanan dan kenyamanan konsumen. Dikarenakan beragamnya produk yang ditawarkan saat ini masyarakat sangat teliti dan tidak ingin dirugikan karena membeli produk yang salah. Mereka ingin produk yang dibeli benar-benar sesuai dengan kebutuhan mereka. Hal ini sesuai dengan yang disampaikan oleh (Swasta dan Irawan, 2002) Produk Merupakan segala sesuatu yang dapat ditawarkan produsen untuk diperhatikan, diminta, dicari, dibeli, digunakan, atau dikonsumsi pasar sebagai pemenuhan kebutuhan atau keinginan pasar yang bersangkutan.

Nilai korelasi rank spearman untuk hubungan Merk terhadap keputusan pembelian sepeda motor Honda Beat pada PT. Nusantara Surya Sakti Cabang Bengkulu dengan nilai korelasi sebesar 0,707 dengan kriteria penelitian kuat. Hal ini diperkuat dengan hasil pengujian hipotesis diketahui nilai thitung $=6,480$ lebih besar dari nilai ttable yaitu 1,681 atau $(6,480>1,681)$. Jadi nilai thitung lebih besar dari ttable. Berarti antara Merk memiliki hubungan yang positif dan signifikan terhadap keputusan pembelian sepeda motor Honda Beat pada PT. Nusantara Surya Sakti Cabang Bengkulu.

Merek adalah sebuah nama, istilah, tanda, simbol, desain atau kombinasinya yang dimaksudkan untuk mengidentifikasi barang dan jasa seorang penjual atau kelompok penjual dan membedakannya dengan pesaingnya (Kotler, 1997). Jadi sebuah produk apabila tidak mempunyai merk yang dikenal dan dipercaya oleh masyarakat maka produk tersebut tidak akan mempengaruhi konsumen dalam mengambil keputusan pembelian. Hal ini berarti Honda Beat sudah memiliki merk yang dipercaya dan dikenal luas oleh lingkungan masyarakat sehingga dapat mendorong seseorang untuk melakukan keputusan pembelian.

Nilai korelasi rank spearman untuk hubungan Promosi terhadap keputusan pembelian sepeda motor Honda Beat pada PT. Nusantara Surya Sakti Cabang Bengkulu dengan nilai korelasi sebesar 0,815 dengan kriteria penilaian sangat kuat. Hal ini diperkuat dengan hasil uji hipotesis diketahui nilai thitung $=9,112$ lebih besar dari nilai ttable 1,681 atau $(9,112>1,681)$. Dengan demikian nilai thitung lebih besar dari ttable, berarti antara Promosi memiliki hubungan yang positif dan signifikan dengan keputusan pembelian sepeda motor Honda Beat pada PT. Nusantara Surya Sakti Cabang Bengkulu.

Promosi adalah salah satu faktor terpenting dalam keputusan pembelian itu terbukti dari hasil korelasi rank spearman bahwa yang memiliki kriteria penilaian tertinggi adalah hubungan promosi terhadap keputusan pembelian. Hal ini dikarenakan Promosi adalah suatu kegiatan memperkenalkan produknya pada pembeli dan masyarakat sehingga mereka tertarik membeli. Betapapun berkualitasnya suatu produk, bila konsumen belum pernah mendengarnya dan tidak yakin bahwa produk itu akan berguna bagi mereka, maka mereka tidak akan pernah membelinya. Supaya merek suatu produk dikenal secara luas oleh konsumen maka perlu sekiranya penjual melakukan kegiatan pemasaran yang lain yaitu promosi. Jadi produk Honda Beat bisa dikatakan melakukan promosi yang sangat baik dengan seringnya mengadakan Gathering kepada pelanggan, 
dan memberikan sponsor2 pada acara2 tertentu, sangatlah berguna untuk bisa menarik perhatian konsumen untuk melakukan keputusan pembelian.

\section{KESIMPULAN DAN SARAN}

\section{Kesimpulan}

1. Hasil pengujian rank spearman terdapat hubungan yang kuat antara produk dengan keputusan pembelian sepeda motor Honda Beat pada PT. Nusantara Surya Sakti Cabang Bengkulu dengan nilai korelasi sebesar 0,646. Untuk Nilai korelasi rank spearman hubungan Merk terhadap keputusan pembelian sepeda motor Honda Beat pada PT. Nusantara Surya Sakti Cabang Bengkulu dengan nilai korelasi sebesar 0,707 dengan kriteria penelitian kuat. Dan Nilai korelasi rank spearman untuk hubungan Promosi terhadap keputusan pembelian sepeda motor Honda Beat pada PT. Nusantara Surya Sakti Cabang Bengkulu dengan nilai korelasi sebesar 0,815 dengan kriteria penilaian sangat kuat

2. Hasil pengujian hipotesis hubungan produk dengan keputusan pembelian diketahui nilai thitung $=5,483$ lebih besar dari nilai ttable yaitu 1,681 atau $(5,483>1,681)$. Jadi nilai thitung lebih besar dari ttable. Berarti antara produk memiliki hubungan yang positif dan signifikan terhadap keputusan pembelian sepeda motor Honda Beat pada PT. Nusantara Surya Sakti Cabang Bengkulu. Hasil pengujian hipotesis hubungan Merk terhadap keputusan pembelian diketahui nilai thitung $=6,480$ lebih besar dari nilai ttable yaitu 1,681 atau $(6,480>1,681)$. Jadi nilai thitung lebih besar dari ttable. Berarti antara Merk memiliki hubungan yang positif dan signifikan terhadap keputusan pembelian sepeda motor Honda Beat pada PT. Nusantara Surya Sakti Cabang Bengkulu. Hasil uji hipotesis hubungan Promosi terhadap keputusan pembelian diketahui nilai thitung $=9,112$ lebih besar dari nilai ttable 1,681 atau $(9,112>1,681)$. Dengan demikian nilai thitung lebih besar dari ttable, berarti antara Promosi memiliki hubungan yang positif dan signifikan dengan keputusan pembelian sepeda motor Honda Beat pada PT. Nusantara Surya Sakti Cabang Bengkulu.

\section{Saran}

1. Variable Promosi memiliki pengaruh yang sangat signifikan terhadap keputusan pembelian sepeda motor Honda Beat pada PT. Nusantara Surya Sakti Cabang Bengkulu, dalam hal ini perusahaan harus memperhatikan lagi cara mempromosikan Produk dan Merk dengan melakukan Promosi yang berhubungan langsung kepada konsumen dan sering- sering mengadakan gathering dan turun langsung ke lokasi untuk memberikan informasi yang lengkap tentang produk dan merk Honda Beat kepada konsumen serta perusahaan harusnya selalu mengikut sertakan sebagai sponsor launching dealer baru atau acara perlombaan dalam bidang touring.

2. Betapapun berkualitasnya suatu produk, bila konsumen belum pernah mendengarnya dan tidak yakin bahwa produk itu akan berguna bagi mereka, maka mereka tidak akan pernah membelinya. Supaya merek suatu produk dikenal secara luas oleh konsumen maka perlu sekiranya penjual melakukan kegiatan pemasaran yang lain yaitu promosi. promosi adalah arus informasi atau persuasi satu arah yang dibuat untuk mengarahkan seseorang atau organisasi kepada tindakan yang menciptakan pertukaran dalam pemasaran. Walaupun Produk, Merk, dan Promosi yang dirasakan pelanggan sudah baik dan sesuai, untuk meningkatkan keputusan pembelian hendaknya perusahaan menyeimbangkan antara produk, merk, dan promosi tersebut agar menjadi satu kesatuan yang utuh demi berlangsungnya kehidupan perusahaan yang jauh lebih baik kedepanya. 


\section{DAFTAR PUSTAKA}

Arikunto, Suharsimi. 2002. Prosedur Penelitian. Edisi Revisi V.PT.Rineka Cipta.Jakarta.

Amstrong, Michael. 2003. Manajemen Sumber Daya Manusia Seri Pedoman Manajemen, (Alih

Bahasa : Sofyan dan Haryanto), Jakarta: Elex Media Komputindo Kelompok Gramedia.

Assauri, Sofian. (2003). Customer Service yang Baik Landasan Pencapaian Customer Satisfaction dalam Usahawan. No. 01, Tahun XXXII, Januari, hal : Jakarta

Assael, Sutisna. 2003. Perilaku Konsumen. Erlangga

Basu, Swastha. 2005. Personal Serling. Penerbit: Liberty. Yogyakarta

Enggel, Blackwell, Miniard. 2004 . Prilaku Konsumen (terjemahan). Edisi Enam.jilid Pertama.Binarupa Aksara.Jakarta.

Engel, dkk . 1994. Perilaku Konsumen (terjemahan). Edisi Tiga Jilid Pertama. Binarupa Aksara Jakarta.

Ferdinand, Augusty. 2000. Manajemen Pemasaran Sebuah Pendekatan Strategik. Semarang : Program Magister Manajemen UNDIP

Fitriadi, Agus.2003. Analisis beberapa factor yang mempengaruhi keputusan dalam pembelian pada UD Microcom di Banjarmasin,Sripksi.Universitas Lambung Mangkurat Banjarmasin.

Juanda, 2009. Metode dan teknik menyusun skripsi. Cetakan kelima, Jakarta

Kotler, Philip.2002.Manajemen Pemasaran (terjemahan).Edisi Millenium, jilid 1.PT. Prenhallindo. Jakarta.

Kotler. 2000. Manajemen Pemasaran Dilndonesia. Jakarta : Salemba Empat

Kotler \& Armstrong. 2001. Prinsip-prinsip Manajemen Pemasaran. Edisi Kedelapan, jilid 1. Penerbit. PT. Erlangga

Nugroho J Setiadi, 2003, Strategic Pemasaran : Konsep dan Implikasi Untuk Strategi dan Penelitian Bisnis Pemasaran, Prenada Media, Jakarta

Riduwan. 2005. Metode dan Teknik Menyusun skripsi, cetakan keempat, Bandung :Alfabeta Singgih. 2004. Metode Penelitian. Penerbit: Fakultas Ekonomi Universitas Indonesia. Jakarta. Stanton, William J .1996. Prinsip Pemasaran (terjemahan). Edisi 7,jilid 1.Erlangga. Jakarta. Sugiyono. 2013. Metode Penelitian Bisnis. Penerbit : Alfabeta. Bandung Supranto, J. 2003. Statistik-Teori dan Aplikasi, Erlangga, Jakarta Swastha, Basu. 2005. Personal Serling. Penerbit: Liberty. Yogyakarta

Tjiptono, Fandi. 2008. Service Manajemen. Penerbit. PT. Prenada Media. Jakarta Timur. 